\title{
Making the cut when applying for jobs online
}

\author{
Jeanne Novak* \\ Bowling Green State University, Bowling Green, OH, USA
}

Accepted November 2016

\begin{abstract}
.
BACKGROUND: Companies are increasingly moving toward the use of web-based hiring practices. Unfortunately, job applicants with disabilities may encounter barriers to accessing and submitting online job applications. Recent research reveals that nearly half of job seekers with disabilities who applied for a job online found the experience to be difficult or impossible.

OBJECTIVE: This article provides job seekers with intellectual and developmental disabilities and those who support them with winning strategies for navigating the online application process.

CONCLUSION: Strategies focus on getting your application through automated filters in applicant tracking systems, making a good first impression, requesting assistance, leveraging your personal connections, and standing out from the crowd.
\end{abstract}

Keywords: Accessibility, job applicants, disabilities, web-based application systems, e-selection, hiring practices

\section{Introduction}

Have you ever experienced the frustration of spending considerable time and effort to complete an online employment application only to have it seemingly disappear into a black hole? Have you encountered problems with technology when trying to complete an employment application on a company's website? If you answered yes to one or both of these questions, you are not alone. It is estimated that over half of job applicants hear nothing back after clicking the submit button on an online application for employment. And research indicates that a majority of job seekers find the challenges of completing online employment applications to be frustrating (Roberts, 2014). If you are a person with a disability, you may experience additional challenges when attempting to use web-based application systems

*Address for correspondence: Jeanne Novak, Bowling Green State University, 413 Education Building, 1001 E. Wooster St., Bowling Green, OH 43403, USA. Tel.: +1 419372 6826; Fax: +1 419372 8265; E-mail: jnovak@bgsu.edu. (e.g., Erickson, von Schrader, Bruyère, VanLooy, \& Matteson, 2014; Lazar, Olalere, \& Wentz, 2012).

Company hiring practices have changed dramatically in recent years (Stone, Lukaszewski, StoneRomero, \& Johnson, 2013; Weber, 2012). Placing job advertisements in newspapers has been largely replaced by the use of job boards and social networking websites to attract, engage, and recruit job candidates. Candidates are increasingly being directed to complete web-based applications for employment, and the information they provide about their knowledge, skills, abilities, and other attributes is often analyzed and scored by automated screening software before a human ever sees it. It is not uncommon for candidates to have little, if any, contact with a company representative during the entire hiring process.

\section{New challenges call for new strategies}

How can you beat the odds and get your foot in the door at companies that utilize web-based 
application systems? This is a question that the Association for People Supporting Employment First (APSE) has heard echoed among job developers and other employment support professionals across the country who assist job seekers with disabilities to navigate the online employment application process. As the prevalence of companies using electronic selection (e-selection) technologies such as online applications and online pre-employment assessments continues to rise (Stone et al., 2013), so too have concerns that individuals with disabilities-particularly those with intellectual and developmental disabilities (IDD) - face new hurdles during the job search. Job developers report, for example, that they have been prevented from assisting job seekers who have limited computer technology skills or low reading levels to complete online applications at in-store computer stations, or kiosks. They also bemoan instances in which an online application session timed out before the job seeker had completed the application. Still others report that they have been unable to locate contact information on the application website for requesting technical assistance or an accommodation. In response to these anecdotal reports, the APSE Research Committee, chaired by Dr. Wendy Parent-Johnson of the University of South Dakota, turned its attention to understanding (a) how the trend toward online recruitment and hiring has altered the ways in which individuals with disabilities approach the job search process, (b) the potential impact of this trend on the employment opportunities and outcomes experienced by job seekers with disabilities, and (c) strategies for assisting individuals with disabilities to successfully navigate the online job search process.

A review of the literature suggests that job seekers with disabilities face unique challenges when applying for jobs online. For example, a study by Bruyère, Erickson, and VanLooy (2006) reveals that online technologies used in human resource (HR) processes are often unintentionally designed in ways that make them inaccessible and unusable to those with disabilities. Many job boards (i.e., websites which posts jobs supplied by employers) and aggregator websites (i.e., job search sites that gather listings from job boards and employer websites into a single location) have been found to be inaccessible (Bruyère, Erickson, \& VanLooy, 2005; Lazar et al., 2011). In addition, web-based job applications are often difficult for individuals with disabilities to access or use (e.g., Lazar, Olalere, \& Wentz, 2012). Results of a 2015 study conducted by the Partnership on Employ- ment and Accessible Technology (PEAT) underscore obstacles encountered by job applicants with disabilities when applying for jobs online. Nearly half (46\%) of study participants who had recently applied for a job online rated the experience as difficult to impossible. Top accessibility issues reported by respondents were "complex navigation, timeout restrictions, poor screen contrast" and "confusing, poorly written, and inconsistent instructions" (PEAT, p. 5). Lack of information about how to request technical support or an accommodation were two other common issues reported by applicants with disabilities. Because $29 \%$ of the sample identified themselves as having cognitive and/or intellectual disabilities, job seekers with IDD likely experience many of the accessibility issues captured in the PEAT survey.

What follows are tips from recruiters, employers, and accessible technology and disability experts for navigating the online application process. An earlier version of the article was presented at the 2016 APSE National Conference in Cincinnati, Ohio on June 22, 2016. Although the strategies presented are targeted to job seekers with IDD and to those who assist them in securing employment, other job seekers may also find the strategies helpful when applying for jobs online.

\section{Navigating the online application process}

How can you get your job application to the top of the stack so that the person making the hiring decision sees it? And are there other things you can do to improve your chances of getting that all-important job interview? The suggestions that follow include both strategies for maximizing your online employment application (Strategies 1-3) and strategies for augmenting or circumventing the online application process through networking and relationship building (Strategies $4 \& 5$ ).

\subsection{Strategy 1: Beat the bot!}

Approximately half of mid-sized companies and most large companies use applicant tracking systems to screen applicants for job openings (Salpeter, 2012). Applicant tracking systems use automated keyword filters to identify candidates whose qualifications and skills dovetail best with specific job requirements (Stone et al., 2013). This saves employers the time of sifting through stacks of applications and resumes to find good candidates. What it means 
for you, as a job applicant, is that before a human ever touches your application, it is scored against potentially hundreds of other applicants by automated screening software designed to weed out applicants. Below are tips for making it past the resume robots and screening algorithms to get your application into the hands of the person who will make the hiring decision:

1. Pursue job openings that closely match your interests, skills, and abilities (Salpeter, 2012). Closely read the description of what the job entails. To increase your chances of making the initial cut, devote your time to applying for jobs for which you are qualified in terms of education, experience, and certifications.

2. Include keywords from the job description in your application. Describing in your cover letter, resume, and/or application responses how your skills and accomplishments address the key requirements of the job will increase your chances of being hired (Mohamed, Orife, \& Wilbowo, 2002). But be careful not to include keywords that are likely to get your application jettisoned by the screening software. For example, if you are applying for a job position that involves handling money, do not use negative keywords such as "stealing" or "fired." Even if you make a statement such as, "I have never been caught stealing" or "I have never been fired from a job," the screening software might flag your application because it does not recognize the context of the keywords you used.

3. Prepare a resume that can easily be digitally imported into the company's applicant tracking system. Do not use headers or footers because they can jam the screening tools. Also avoid using graphics, fancy fonts or formatting, and abbreviations (Cappelli, 2012).

By taking these steps, you will increase your chances of passing the first checkpoint on your job application journey.

\subsection{Strategy 2: Make a good first impression}

Congratulations! You beat the bot and your application has made its way to the hiring manager's desk. To make a good first impression, complete your application with the following suggestions in mind:

1. Respond to every field of the online application (Salpeter, 2012). This demonstrates your interest in the job as well as your attention to detail. Many HR professionals simply pass over applications that are not filled out completely.

2. Review the entire application for spelling, content, and grammar errors before hitting the submit button (Salpeter, 2012). Remember, once you hit that button, you cannot go back to make additional changes to your application. Poorly written applications are likely to be tossed out.

3. Make sure your online presence is working for you, not against you (Mackelden, 2013). Employers are becoming ever more likely to research the social media profiles of job applicants in an effort to uncover their true character and attributes. Therefore, it is wise to periodically review your profiles on social networks such as LinkedIn and Facebook to ensure that there are no public images or content that could deter an employer from hiring you.

First impressions are important. Following these suggestions will help you make a positive first impression when you apply for a job online.

\subsection{Strategy 3: Request assistance}

What if you need assistance or an accommodation to complete a job application on a company's website? Maybe you don't understand the instructions, you are having difficulty navigating the application website, or the application times out before you are finished typing responses to a pre-employment assessment such as a cognitive ability test or personality inventory. Such difficulties could result in you being inadvertently screened out before reaching the next step in the job application process.

If you have difficulty completing the online application, look on the company website for instructions for requesting technical assistance or an accommodation. You may be able to find a helpdesk email address in the application instructions or on a Frequently Asked Questions (FAQ) tab. According to a recent study, $58 \%$ of employers provide advance notice to job applicants indicating that reasonable accommodations are available during the employment application process (Erickson et al., 2014). For example, a company may include an equal employment opportunity policy statement on their career home page such as the following: Company A provides reasonable accommodations in the application process for persons with disabilities. If you need 
assistance to accommodate a disability, please contact a member of the management team at your nearest Company A store. If you are directed to contact someone at the local store level, take advantage of this opportunity to meet face-to-face with the hiring manager!

A growing number of companies use in-store computer stations, or hiring kiosks, for screening job applicants (Doyle, 2016). If you do not have access to a computer with an Internet connection, completing an application at an in-store kiosk may be an efficient alternative to completing the application online. Be sure to bring your personal information and detailed work history so that you can complete the application in one sitting. See Strategy 5 for advantages of having a comprehensive resume to take with you. If you have limited computer skills, it is reasonable to ask a staff member (or an employment support professional) to enter data into the web-based system for you as long as such skills are not needed to perform the essential function of the job (Stone et al., 2013). If you have a question while completing the application, you can use it as an opportunity to introduce yourself to someone in HR and to show enthusiasm for the company and its products. Employers recognize that loyal customers often make the best employees, so giving them a face to go with the name on your application can work to your advantage.

The strategies described to this point focus primarily on ways to improve your chances of securing a job interview when applying online for a publicized job opening. From this viewpoint, the job application serves as a gatekeeper that controls access to the next step in the job search process. The strategies that follow take a broader view of the job search process, one that reflects supported and customized employment approaches to job development with their emphasis on networking and relationship building (Griffin, Hammis, \& Geary, 2007; Luecking, Fabian, \& Tilson, 2004).

\subsection{Strategy 4: Leverage personal connections}

A common belief among job seekers is that if a company website directs interested parties to complete a web-based or kiosk application for employment, this is the only route that can be taken to pursue an interest in working for the company, and job seekers are expected to have no interaction with anyone from the company unless and until they win the job application lottery. Happily, this is untrue. Many job openings are never publicly advertised. Instead, many positions are filled through word-of-mouth or networking (Hansen, n.d.). Employers prefer to hire a known entity, perhaps a friend of someone who works for the company or a person recommended by a member of a local business association or service club to which they belong (Luecking, et al., 2004). Getting a referral from someone in the company is often the best way to get an interview. If the referral comes with a personal recommendation, this is even better.

If you become aware of a job position that may be a particularly good fit for you (or a job seeker you are supporting), enlist any connections you have with employees at the company. Hansen recommends to the job seeker, "The best place to start developing your network is with your family, friends, and neighbors - and with their family, friends, and neighbors" (para. 3). Savvy job developers reach out to businesses through people who know a job seeker well, while also tapping their own relationships with businesses (Migliore, Butterworth, Nord, Cox, $\&$ Gelb, 2012). Research on employer recruitment practices underscores the importance of networking. Results of the 2010 Kessler Foundation/NOD Survey of Employment of Americans with Disabilities (Harris Interactive, 2010) indicate that employers who hire people with disabilities are most likely to recruit through employee referrals $(70 \%)$, followed by friends or word-of-mouth referrals $(60 \%)$. They were less likely to use online job boards $(58 \%)$ or community-based or state/federal service provider agencies $(50 \%)$.

Many companies have employee referral programs. An employee referral program rewards employees who recommend qualified friends, relatives, or colleagues for position openings. These programs are popular with employers because employees with good work performance tend to refer others who will also make good employees, thereby saving the employer time and money in the recruitment process. Added benefits for you as the job seeker are that the employee who referred you will have a vested interest in your ultimate success with the company after hire and you will already be connected to at least one person in your new organization (Ryan, 2015). Encourage friends and family members who work in companies with employee referral programs to refer you for a position in which you are interested. To sum up the advice from career experts: Take the job search into your own hands by tapping your personal and professional networks! 


\subsection{Strategy 5: Stand out from the crowd}

But how can you get your application noticed if you do not have a personal connection with anyone at the company? Susan Davis, Supported Employment Program Coordinator at The Center for Disability Resources, a University Center for Excellence in Developmental Disabilities (UCEDD) at the University of South Carolina, has some excellent advice for job developers on how to successfully navigate the job search process (personal communication, November 18, 2016). Consistent with Migliore et al. (2012), Davis stresses that simply searching online for job openings and submitting applications for those positions is unlikely to result in a job offer. While conventional wisdom suggests that job seekers should complete an employment application as the first step in pursuing a job opportunity, Davis indicates that she instead makes the job seeker's skills and interest in a position known to the employer before ever going to the company's job application website. Here are Davis's top suggestions for helping a job seeker shine over other applicants for a job:

1. Confirm the company is hiring. Davis says she rarely relies on job boards such as Indeed, Monster, and Snagajob because companies may have job descriptions posted on these sites even if they are not currently hiring for those positions at the local store level. Instead, Davis says she goes directly to a company's website to determine if the company is, in fact, hiring for the position in which the job seeker is interested.

2. Prepare a strong resume. Davis describes the resume as "a universal tool for a job search," a tool that is particularly instrumental for job seekers who have difficulty communicating their skills and experiences to prospective employers. According to Davis, a resume highlighting the unique strengths of an individual who has limited work experience can be submitted as part of online application or handed to an employer at a job interview. Equally important, says Davis, a resume can serve as a template from which the job seeker can directly copy information about his or her education and training, job-relevant experiences, transferable job skills, schedule availability, and references onto an online or kiosk application. An added benefit, Davis explains, is that if the application asks, "Did you complete this application yourself?" the individual will be able to answer yes.

3. Lay the groundwork before completing an online application. Davis describes her approach to supporting individuals in the job search process as nontraditional. She states, "I never use the online application as a way to get in ... never. It's already a done deal before we sit down to complete the application." By way of example, she explains how she would assist a job seeker named Sam to stand out from other job candidates: First, if Davis learns of a possible job opening that would be of interest to Sam, she visits the business and introduces herself to the direct hiring manager by saying, "I'm looking for a job opportunity for Sam and am curious if you are hiring for any particular positions right now." Davis says her goals at this point in the conversation are to build rapport and to learn about available positions. Second, if Davis sees a good job match between the needs of the business and Sam's interests and talents, she highlights what it is about Sam that makes him the best person for that job. Third, she asks about the application process. If the manager directs her to the company website to complete an application, she says something like, "I think Sam would be very interested in this position. If he goes online and completes the application, can we stop by or call and let you know he's completed it?" More often than not, the manager obliges. Finally, after submitting the application, Davis and/or Sam return to the business to leave Sam's resume for the manager. Attached to the resume is a handwritten note that says something like, "I have applied and am very interested in working for you. Sam.” By establishing rapport with the hiring manager and showcasing Sam's personality, qualifications, and desire for the job, Davis has increased that likelihood that Sam will get an in-person interview.

4. Make it personal. Some businesses require that the online job application be completed as the first step in the application process. If you must complete the online application first, Davis suggests personally following up with someone at the business after the application is submitted. For example, if Sam has applied for a job online, he may write a handwritten note to the hiring manager that states, "I am Sam. I completed my application and I would really like to be able to 
work at your business. Thank you for giving me the chance to apply. You can contact me at \#\#\#-\#\#\#-\#\#\#\# or Susan who is helping me at \#\#\#-\#\#\#-\#\#\#\#." The note is attached to a resume and delivered to the hiring manager or left for him or her at the Customer Service counter.

According to Stone, Deadrick, Lukaszewski, and Johnson (2015), research on the use of technology for recruitment finds that "current e-recruiting practices may be extremely impersonal, passive, and create an artificial distance between applicants and organizations" (p. 281). Davis illustrates the value of making a personal connection to bridge this distance:

If you are a hiring manager who has received 50 online job applications for a single position and you had one person who took the time to write you a personalized note saying they really wanted to work with you, wouldn't you remember that applicant when it came time to arrange interviews? (personal communication, November 18, 2016).

The strategies shared by Davis are designed to give a qualified applicant with IDD an edge in securing a job interview. She concludes by stating that her overarching goal throughout the job search and negotiation process is to create a win-win situation for both the employer and the job seeker.

\section{Conclusion}

The prospect of searching for a job online can be daunting. The sheer numbers of applicants for many job openings, difficulties in navigating some application websites, and the sense that one's fate is being determined by an impersonal computer program may cause job seekers to view the entire online job application process as frustrating and unproductive. For individuals with IDD and those who assist them in securing employment, the pervasiveness of webbased application systems requires the use of slightly new or enhanced employment support strategies. The suggestions shared in this article are intended to equip job seekers with winning strategies for negotiating the online application process. Companies want to find and hire individuals with the best mix of attributes and skills to fill open positions. Ensuring that all qualified individuals—including those with IDD—can participate in the recruitment and hiring process is key to achieving this goal.

\section{Conflict of interest}

The authors have no conflict of interest to report.

\section{References}

Bruyère, S., Erickson, E., \& VanLooy, S. (2005). Information technology and the workplace: Implications for persons with disabilities. Disability Studies Quarterly, 25(2). Retrieved from http://dsq-sds.org/article/view/548/725

Bruyère, S., Erickson, E., \& VanLooy, S. (2006). Information technology (IT) accessibility: Implications for employment of people with disabilities. Work, 27(4), 397-405.

Cappelli, P. (2012). Why good people can't get jobs: The skills gap and what companies can do about it. Philadelphia, PA: Wharton Digital Press.

Doyle, A. (2016). Applying for a job at a hiring kiosk [Blog post]. Retrieved from https://www.thebalance.com/applyingfor-a-job-at-a-hiring-kiosk-2061572

Erickson, W. A., von Schrader, S., Bruyère, M., VanLooy, S. A., \& Matteson, S. (2014). Disability-inclusive employer practices and hiring of individuals with disabilities. Rehabilitation Research, Policy, and Education, 28(4), 309-328.

Griffin, C., Hammis, D., \& Geary, T. (Eds.). (2007). The job developer's handbook: Practical tactics for customized employment. Baltimore, MD: Brookes.

Hansen, R.S. (n.d.). Networking your way to a new job [Blog post]. Retrieved from the Quintessential website: https://www.livecareer.com/quintessential/networking-guide

Harris Interactive (2010). Kessler Foundation/NOD Survey of Employment of Americans with Disabilities. Retrieved from http://www.2010disabilitysurveys.org/octsurvey/pdfs/survey results.pdf

Hu, J. (2016). Eight things you need to know about applicant tracking systems [Blog post]. Retrieved from https://www.jobscan.co/blog/8-things-you-need-to-knowabout-applicant-tracking-systems/

Lazar, J., Olalere, A., \& Wentz, B. (2012). Investigating the accessibility and usability of job application web sites for blind users. Journal of Usability Studies, 7(2), 68-87.

Lazar, J., Wentz, B., Biggers, D., Delair, J., Donnelly, M., Kashim, E., ...\& Yun, J. (2011). Societal inclusion: Evaluating the accessibility of job placement and travel web sites. Proceedings of the INCLUDE 2011 Conference, London, UK, Royal College of Art. Retrieved from http://www.hhc.rca.ac.uk/ 3845/all/1/proceedings.aspx

Luecking, R. G., Fabian, E. S., \& Tilson, G. P. (2004). Working relationships: Creating career opportunities for job seekers with disabilities through employer partnerships. Baltimore, MD: H. Brookes.

Mackelden, L. (2013). How do big recruiters recruit online? Retrieved from http://www.onrec.com/news/features/onreconline-recruitment-magazine-feature-how-do-big-recruitersrecruit-online

Migliore, A., Butterworth, J., Nord, D., Cox, M., \& Gelb, A. (2012). Implementation of job development practices. Intellectual and Developmental Disabilities, 50(3), 207-218.

Mohamed, A. A., Orife, J. N., \& Wibowo, K. (2002). The legality of key word search as a personnel selection tool. Employee Relations, 24, 516-522. 
Partnership on Employment \& Accessible Technology (PEAT; 2015). eRecruiting \& accessibility: Is technology hurting your bottom line? A report on PEAT's 2015 research findings. Retrieved from http://peatworks.org/content/erecruitingaccessibility-report

Roberts, M. (2014). Top takeaways from the 2014 Jibe Talent Acquisition Survey [Blog post]. Retrieved from https:// www.jibe.com/blog/top-takeaways-from-the-2014-jibetalent-acquisition-survey/

Ryan, L. (2015). The truth about employee referrals [Blog post]. Retrieved from Forbes website: http://www.forbes.com/ sites/lizryan/2015/01/23/the-truth-about-employee-referrals/ \#7282976f1f13

Salpeter, M. (2012). The 9 best tips for submitting an online job application [Blog post]. Retrieved from U.S. News and World Report website: http://money.usnews.com/money/ blogs/outside-voices-careers/2012/07/11/the-9-best-tips-forsubmitting-an-online-job-application
Stone, D. L., Deadrick, D. L., Lukaszewski, K. M., \& Johnson, R. (2015). The influence of technology on the future of human resource management. Human Resource Management Review, 25, 216-231. doi:10.1016/j.hrmr.2015.01.002

Stone, D. L., Lukaszewski, K. M., Stone-Romero, E. F., \& Johnson, T. L. (2013). Factors affecting the effectiveness and acceptance of electronic selection systems. Human Resource Management Review, 23(1), 50. doi:10.1016/j.hrmr.2012.06.006

Weber, L. (2012). Your résumé vs. oblivion: Inundated companies resort to software to sift job applications for right skills [Blog post]. Retrieved from The Wall Street Journal website: http:// www.wsj.com/articles/SB1000142405297020462420457717 8941034941330 